\title{
Vaginal Touch versus Transvaginal Ultrasound in the Management of Threatened Preterm Labour at the University Hospital Center of Porto-Novo (Benin)
}

\author{
Ogourinde Mathieu Ogoudjobi*, Christiane Tshabu-Aguemon, Megnisse S. H. S. Lokossou, \\ M. Veronique Tognifode, Moufalilou Aboubakar, Gounou Didier Komongui, \\ Joseph Lanwassonou, Angéline Tonato Bagnan, Antoine Lokossou, Issifou Takpara, \\ René-Xavier Perrin
}

Faculty of Health Sciences, University of Abomey-Calavi, Cotonou, Benin

Email: *mgoudjobi2014@gmail.com

How to cite this paper: Ogoudjobi, O.M., Tshabu-Aguemon, C., Lokossou, M.S.H.S., Tognifode, M.V., Aboubakar, M., Komongui, G.D., Lanwassonou, J., Bagnan, A.T., Lokossou, A., Takpara, I. and Perrin, R.-X. (2017) Vaginal Touch versus Transvaginal Ultrasound in the Management of Threatened Preterm Labour at the University Hospital Center of Porto-Novo (Benin). Open Journal of Obstetrics and Gynecology, 7, 1141-1149.

https://doi.org/10.4236/ojog.2017.711115

Received: September 25, 2017

Accepted: October 27, 2017

Published: October 30, 2017

Copyright $\odot 2017$ by authors and Scientific Research Publishing Inc. This work is licensed under the Creative Commons Attribution International License (CC BY 4.0).

http://creativecommons.org/licenses/by/4.0/

(c) (i) Open Access

\begin{abstract}
Objective: To evaluate the risk of preterm delivery with vaginal touch in opposition with transvaginal ultrasound in pregnant women who present signs and symptoms of threatened preterm labour. Methods: A prospective study was conducted with descriptive and comparative aims at the University Hospital of Porto-Novo, Benin Republic between 1 March and 31 August 2016. Every pregnant woman admitted to the emergencies of the maternity between 28 and 34 of WA (weeks of amenorrhoea) and attended for preterm delivery risk with intact membranes was included. The risk of preterm delivery was evaluated using vaginal touch and ultrasound examination of cervical length. Results: The risk of preterm delivery was obvious and identical with the cervical dilatation $\geq 2 \mathrm{~cm}$ when the vaginal touch was applied [RR 2.34 IC 95\% $(1.71-3.20)]$ and ultrasound examination of cervical length $<25 \mathrm{~mm}$ [RR 2.44 IC 95\% (1.43 - 4.16)]. The cervix obliteration was not statistically linked to preterm delivery. The ultrasound examination of cervical length had a better sensitivity $(87.76 \%)$ and a negative predictive value (81.54\%) against $59.18 \%$ and $74.68 \%$ respectively for cervical dilatation at vaginal touch. Bishop score also had a better specificity with the one of the ultrasound examination of cervical length $(79.11 \%$ vs. $33.54 \%)$ whereas both of them had almost identical negative predictive value ( $81.17 \%$ vs. $81.54 \%)$. Conclusion: Vaginal touch was also as relevant as transvaginal ultrasound while evaluating the risk of preterm delivery. For the lack of ultrasound in emergency rooms, a good physical examination would be sufficient by its own to decide of an adequate management when there is a threat of preterm delivery.
\end{abstract}




\section{Keywords}

Threat of Preterm Delivery, Vaginal Touch, Transvaginal Ultrasound, Comparison

\section{Introduction}

Threatened preterm delivery (TPD) is characterised by regular and painful uterine contractions associated with cervical changes which occur between 22 and 36 weeks of amenorrhoea (WA) +6 days. These contractions result in preterm labour in the absence of treatment [1] [2] [3]. Not only is preterm labour a public health problem, worldwide and especially in Africa, due to its frequency, but especially also due to its consequences. As a matter of fact, despite the gaps recorded from one series to another, preterm labour frequency remains high and varies between $10 \%$ up to $50 \%$ according to the studies at stake. It also represents from $75 \%$ up to $85 \%$ of perinatal morbidity and mortality [4]. An adequate evaluation is then requisite in the case of a threatened preterm delivery for a quick and proper management. Although vaginal touch is a medical examination of reference, transvaginal ultrasound is more and more advised for the cervical assessment.

\section{Objective}

To evaluate the risk of preterm labour with vaginal touch versus transvaginal ultrasound examination in pregnant women who present signs and symptoms of threat of preterm delivery.

\section{Patients and Methods}

The present research is a prospective study with descriptive and comparative aims carried out at the maternity of University Hospital Center of Porto-Novo, Benin, between 1 March and 31 August 2016. Sampling was systematic. This research involves every pregnant woman admitted in the emergency department of the maternity between $28 \mathrm{WA}$ and $34 \mathrm{WA}$ with monofetal pregnancies, outset of gestation and also the management of threat of preterm delivery with intact membranes. The TPD diagnosis was deducted when regular and painful uterine contractions occur, associated with cervical change. Cases of uterine malformation or cervico-isthmus gap were also involved. When they are admitted, every pregnant woman benefited, from a practitioner (a gynaecologist or a midwife), a physical examination which includes vaginal touch which allowed to assess the different items of Bishop score (position, obliteration, dilatation, cervical consistency, foetal presentation height). Ultrasound assessment of cervical length was carried out using transvaginal catheter of $6.5 \mathrm{MHz}$ covered with condom for each pregnant woman in supine position (sleeping on the back) with an empty bladder. Once the catheter is introduced in the vagina with a light pressure on 
the cervix, in sagittal section, three measures of cervical length (the distance between the internal orifice and external orifice of the cervical canal) were taken and the smallest value was deducted. We carried out the ultrasound ourselves just after the physical examination in a room where the intimacy of the pregnant women was preserved. The outcome of the pregnancies (preterm delivery $<37$ WA or term delivery $\geq 37 \mathrm{WA}$ ) was assessed according to various parameters of vaginal touch and the ultrasound examination of cervical length (the threshold was set at $25 \mathrm{~mm}$ ). The diagnostic value of each parameter was assessed with the calculation of sensitivity $(\mathrm{Sn})$, calculation of specificity (Sp), positive predictive value (PPV), Negative predictive value (NPV), Positive (LR+) and Negative (LR-) Likelihood Ratio. The collected data were analysed with SPSS 20.0 software. Pearson Chi square test was used with a level of the significant difference at $0.05 \%$.

The study was carried out after the administrative authorities had given their agreement. The objectives of the study were explained to participants. Voluntary informed oral consent was obtained from each participating woman. This consent claims that participants were not at risk by refusing to participate in the study or stopping their collaboration during the study and would not have their maternity care impacted in any way prior to commencing the data collection. The confidentiality of the data and the anonymity of the pregnant were respected.

\section{Results}

1786 obstetric admissions, among which 332 TPD cases, that is a prevalence of $18.6 \%$ were recorded. Nevertheless, 256 pregnant women meet the criteria. After the transvaginal ultrasound was performed, it was noted that the cervical length was less than $25 \mathrm{~mm}$ in 191 pregnant women and it was higher than or equal to $25 \mathrm{~mm}$ in 65 pregnant women.

\subsection{Characteristics of the Sample}

The average age of the sample population was $26.9+/-4.6$. As far as their occupations are concerned, most of the pregnant women were craftswomen (89/256 or $34.8 \%)$ and housewives (84/256 or $32.8 \%)$. Students and civil servants represented respectively $18.7 \%(48 / 256)$ and $13.7 \%(35 / 256)$. In fact of these women (205/256 or $80.1 \%$ ) were non-educated or most of them had little education. Those who reached the secondary or university level were only $19.9 \%(51 / 256)$. The average number of pregnancies comprised $3.81+/-2.05$ and the mean parity was $3.51+/-2.45$. An antecedent of caesarean was diagnosed in $37.1 \%$ of cases. The targets of this study were multiparous (46.5\%), pauciparous (22.3), primiparous (16.4\%), nulliparous (14.8\%) women. The diagnosed pathologies which are considered to be the major causes of threat of preterm delivery were urinary infection (46.9\%), malaria (25.4\%), myoma (12.5\%), previa placenta $(9.4 \%)$ and hydramnios (7\%). All the pregnant women went through tocolysis either on salbutamol (59\%) or nifedipine (41\%). Prenatal corticosteroid therapy (75.8\%), 
antibiotic therapy (55.5\%) and antimalarial treatment (27.7) were the other therapeutic administered.

\subsection{Evaluation of Preterm Delivery Threat Using Parameters of Vaginal Touch and Transvaginal Ultrasound}

On the 256 pregnancies of the present study, 98 (38.3\%) had preterm delivery $(\mathrm{PD}+)$ and $158(61.7 \%)$ had term delivery (PD-). The average cervical length was $19.5 \mathrm{~mm}$ within the group (PD+) and $26.6 \mathrm{~mm}$ in other group (PD-). The cervical dilatation $\geq 2 \mathrm{~cm}$ using vaginal touch and cervical length $<25 \mathrm{~mm}$ at transvaginal ultrasound were correlated to spontaneous preterm delivery with respective approximant risks of 2.34 IC $95 \%(1.71$ - 3.20) and 2.44 IC 95\% (1.43 4.16) (Table 1).

With all the items of Bishop Score, the approximant risk was 3.59 IC 95\% (2.5 - 5.12). The presence of membranes sacculation at transvaginal ultrasound showed an approximant risk more or less greater than 3.84 IC 95\% (2.71 - 5.43). As far as cervical dilatation is concerned, it was not statistically associated with preterm delivery (Table 1 ).

The ultrasound examination of cervical length of the inferior neck at $25 \mathrm{~mm}$ had better sensitivity $(87.76 \%)$ and the better negative predictive value $(81.54 \%)$ against $59.18 \%$ and $74.68 \%$ respectively for cervical dilatation $\geq 2 \mathrm{~cm}$ at vaginal touch. Bishop score, which involves all the items of vaginal touch, presented a better specificity than the one of the ultrasound examination of cervical length (79.11\% vs. $33.54 \%)$ whereas both of them have almost identical negative predictive value $(81.17 \%$ vs. $81.54 \%)$. The presence of a sacculation during the transvaginal ultrasound was more specific (82.91\%) (Table 2).

\section{Discussion}

Several studies showed that incidence of preterm labour and the reduction of ultrasound cervical length in case of TPD [5] [6] [7] are interrelated. The accuracy of this ultrasound cervical measurement in case of TPD varies in consideration to different parameters, especially the gestational age and the level of the fixed cervical length. The shorter is the cervical length at an early ultrasound and the higher is the risk of preterm delivery [8].

For Guzman [8] and Sotiriadis [9], the sensitivity and the negative predictive value of cervical length reduce from 28 WA to $34 \mathrm{WA}$ to score respectively from $94 \%$ and $99 \%$ to $76 \%$ and $96 \%$. The recommendations of the National Authorities for Health in France specified that ultrasound cervical measurement is no more necessary after $34 \mathrm{WA}$; likewise it is valid for twin pregnancy or for asymptomatic patients who do not show any diagnosed sign of spontaneous preterm delivery [10].

This is the reason why the present study excluded twin gestations and limited the gestational age to $34 \mathrm{WA}$. The level of cervical length varies from a study to another (15 mm, $20 \mathrm{~mm}, 25 \mathrm{~mm}$ and $30 \mathrm{~mm}$ ) (Table 3). 
Table 1. Evaluation of preterm delivery threat using parameters of vaginal touch and transvaginal ultrasound in case of TPD.

\begin{tabular}{|c|c|c|c|c|}
\hline & Total & $(\mathrm{PD}+) \mathrm{n}(\%)$ & $(\mathrm{PD}-) \mathrm{n}(\%)$ & $\mathrm{p}$ \\
\hline Bishop score & 102 & $69(67.6)$ & $33(32.3)$ & 0.000 \\
\hline$\geq 7$ & 154 & $29(18.8)$ & $125(81.2)$ & \\
\hline \multicolumn{5}{|l|}{$<7$} \\
\hline Cervical dilatation & 98 & $58(59.2)$ & $40(40.8)$ & $0.012 \times 10^{-4}$ \\
\hline$\geq 2 \mathrm{~cm}$ & 158 & $40(25.3)$ & $118(74.7)$ & \\
\hline \multicolumn{5}{|l|}{$<2 \mathrm{~cm}$} \\
\hline Cervical obliteration & 216 & $84(38.9)$ & $132(61.1)$ & 0.642 \\
\hline$\geq 50 \%$ (short neck and/or obliterated) & 40 & $14(35.0)$ & $26(65.0)$ & \\
\hline \multicolumn{5}{|l|}{$<50 \%$ (long neck and/or mid-long) } \\
\hline \multicolumn{5}{|l|}{ Ultrasound cervical length (mm) } \\
\hline$<25$ & 191 & $86(45.0)$ & $105(55.0)$ & $0.014 \times 10^{-2}$ \\
\hline$\geq 25$ & 65 & $12(18.5)$ & $53(81.5)$ & \\
\hline \multicolumn{5}{|l|}{ Sacculation of membranes } \\
\hline Yes & 95 & $68(71.6)$ & $27(28.4)$ & 0.000 \\
\hline No & 161 & $30(18.6)$ & $131(81.4)$ & \\
\hline Total & 256 & 98 & 158 & \\
\hline
\end{tabular}

Table 2. Predictive values of vaginal touch parameters and ultrasound cervical length in case of TPD.

\begin{tabular}{ccccccc}
\hline & Sn (\%) & Sp (\%) & PPV (\%) & NPV (\%) & LR+ & LR- \\
\hline Bishop $\geq 7$ & 70.41 & 79.11 & 67.65 & 81.17 & 3.74 & 0.36 \\
Cervical obliteration $\geq 50 \%$ & 85.71 & 16.46 & 38.89 & 65.00 & 1.02 & 0.87 \\
Cervical dilatation $\geq 2 \mathrm{~cm}$ & 59.18 & 74.68 & 59.18 & 74.68 & 2.34 & 0.55 \\
Ultrasound cervical length $<25 \mathrm{~mm}$ & 87.76 & 33.54 & 45.03 & 81.54 & 1.32 & 0.36 \\
Sacculation & 69.39 & 82.91 & 71.58 & 81.37 & 4.06 & 0.34 \\
\hline
\end{tabular}

The analysis of table III shows that in order to assess the relevance of ultrasound cervical length, the level to be chosen can vary depending on the higher sensitivity or the higher specificity or even the higher negative predictive value one prefers.

Some studies compared data of vaginal touch with ultrasound cervical measurement in the prediction of spontaneous prematurity in the state of threat of preterm labour (TPD). It was reported that pelvic examination is not efficient for cervix internal orifice assessment because the internal orifice of cervix is not most of the time attainable. It presents an important number of wrong negatives and wrong positives and also a poor reproducibility [11]. Nevertheless, the risk of spontaneous preterm delivery is correlated to cervical dilatation. This risk is 
Table 3. Predictive values of ultrasound cervical measurement for spontaneous preterm delivery according to the findings of previous studies.

\begin{tabular}{|c|c|c|c|c|c|c|c|c|}
\hline & (n) & Level (mm) & Sn (\%) & Sp (\%) & PPV (\%) & NPV (\%) & LR+ & LR- \\
\hline \multirow[t]{2}{*}{ Compan et al. [11] } & $(451)$ & $<25$ & 88.00 & 59.00 & & & 2.09 & 0.20 \\
\hline & & $<30$ & 88.00 & 40.00 & & & 1.47 & 0.30 \\
\hline \multirow[t]{2}{*}{ Sotiriadis et al. [9] } & (122) & $<15$ & 83.30 & 95.80 & 55.60 & 98.90 & 19.8 & 0.17 \\
\hline & & $<25$ & 83.30 & 77.10 & 18.50 & 98.70 & 3.64 & 0.22 \\
\hline Gonzalez et al. [12] & (192) & $<30$ & 97.20 & 31.40 & 24.60 & 98.00 & 1.42 & 0.09 \\
\hline Deplagne et al. [13] & (111) & $\leq 20$ & 75.00 & 52.00 & 21.00 & 92.00 & 1.56 & 0.48 \\
\hline \multirow[t]{2}{*}{ Benichou et al. [14] } & (537) & $<25$ & 59.00 & 85.00 & 45.00 & 91.00 & 3.93 & 0.48 \\
\hline & & $<30$ & 81.00 & 65.00 & 46.00 & 90.00 & 2.31 & 0.29 \\
\hline \multirow[t]{2}{*}{ Sotiriadis et al. [15] } & $(2114)$ & $\leq 15$ & 59.90 & 90.50 & & & 6.31 & 0.44 \\
\hline & & $<25$ & 78.30 & 70.80 & & & 2.68 & 0.31 \\
\hline \multirow[t]{2}{*}{ Berthelot-Ricou [16] } & $(181)$ & $\leq 15$ & 61.80 & 83.50 & 75.30 & 72.80 & 1.74 & 0.46 \\
\hline & & $\leq 20$ & 83.10 & 52.30 & 58.70 & 72.20 & 1.47 & 0.32 \\
\hline Demirci et al. [17] & (209) & $\leq 15$ & 78.90 & 94.20 & & & 13.64 & 0.22 \\
\hline \multirow[t]{2}{*}{ Palacio et al. [18] } & (333) & $\leq 15$ & 28.60 & 96.50 & & & 8.1 & 0.74 \\
\hline & & $<25$ & 71.40 & 79.20 & & & 3.43 & 0.36 \\
\hline Bagga et al. [19] & $(100)$ & $<25$ & 60.00 & 96.90 & & & 19.5 & 0.41 \\
\hline
\end{tabular}

higher when the cervix is more dilated [8] [20]. For some researchers [8] [11] [21] [22], there are no significant scientific arguments to consider that between cervix assessment with transvaginal ultrasound or with pelvic examination, one of the methods being superior to the other to predict spontaneous preterm delivery in pregnant women with preterm delivery threat because both of the methods are complementary. However, cervical ultrasound may be more reproducible and less subjective than the assessment of cervix by pelvic examination. This reproducibility associated with excellent negative predictive value made those authors recommend cervical ultrasound to decide of the hospitalization or an in-utero transfer in case of preterm delivery.

In the case of the present study, the ultrasound examination of cervical length less than $25 \mathrm{~mm}$ had the best sensitivity (8.76\%) and the best negative predictive value (81.54\%) against $59.18 \%$ and $74.68 \%$ respectively for cervical dilatation $\geq 2$ $\mathrm{cm}$ for pelvic examination. Bishop score which involves all the items of pelvic examination had a specificity better than the one of ultrasound examination of cervical length (79.11\% vs. $33.54 \%)$ whereas both had almost identical negative values $(81.17 \%$ vs. $81.54 \%$ ). Both parameters (cervical dilatation $\geq 2 \mathrm{~cm}$ and cervical length $<25 \mathrm{~mm}$ ) were correlated to preterm delivery with respective related risks of 2.34 IC $95 \%(1.71-3.20)$ and 2.44 IC $95 \%$ (1.43 - 4.16). With Bishop Score, the related risk was 3.59 IC $95 \%(2.52-5.12)$. As far as cervical obliteration is concerned, it was not statistically associated with preterm delivery. 
The limitations of this study are the limited size of the sample. However, the results generated by the study are in agreement with the data from the scientific literature.

\section{Conclusion}

Vaginal touch examination was also as relevant as transvaginal ultrasound in the assessment of the risk of preterm delivery in pregnant women with signs of threatened preterm delivery with intact membranes so as the superiority of one over the other could not be affirmed. This depends on the choice made between the sensitivity, the specificity or the negative predictive value. For lack of ultrasound in emergency rooms, a good physical examination would be enough for an adequate management of a threatened preterm delivery. Other studies on large cohorts will be useful to reinforce our results.

\section{Acknowledgements}

Authors are very grateful to women who participated in the study and also would like to thank the administrative authorities and staff members of University Hospital Center of Porto-Novo.

\section{Conflict of Interests}

The authors do not declare any conflicts of interest.

\section{References}

[1] Suhag, A. and Berghella, V. (2015) Short Cervical Length Dilemma. Obstetrics and Gynecology Clinics of North America, 42, 241-254. https://doi.org/10.1016/j.ogc.2015.01.003

[2] Martin, J.A., Hamilton, B.E., Sutton, P.D., et al. (2010) Births: Final Data for 2008. National Vital Statistics Reports, 59, 1-72.

[3] Saint Leger, S. (1999) Management of a Threat of Premature Delivery. Development and Health, No. 140, 12-21.

[4] Goffinet, F., Kayem, G., Le Bret, T., Schmitz, T., Maillard, F. and Cabrol, D. (1999) New Markers of the Risk of Preterm Delivery. Update of the National College of French Gynecologists and Obstetricians, Tome XXIII, 43-95.

[5] Sy, T. and Diallo, F. (2010) Threat of Preterm Delivery: Use of Nifedipine at the Ignace DEEN Hospital in Conakry. Tropical Medicine, 70, 141-144.

[6] Tsoi, E., Akmal, S., Rane, S., Otigbah, C. and Nicolaides, K.H. (2003) Ultrasound Assessment of Cervical Length in Threatened Preterm Labor. Ultrasound in Obstetrics \& Gynecology, 21, 552-555. https://doi.org/10.1002/uog.131

[7] Benoist, G. (2016) Prediction of Preterm Delivery in Symptomatic Women (under Threat of Premature Delivery). Journal de Gynécologie Obstétrique et Biologie de la Reproduction, 45, 1346-1363. https://doi.org/10.1016/j.jgyn.2016.09.025

[8] Guzman, E.R., et al. (2001) A Comparison of Sonographic Cervical Parameters in Predicting Spontaneous Preterm Birth in High-Risk Singleton Gestations. Ultrasound in Obstetrics \& Gynecology, 18, 204-210.

https://doi.org/10.1046/j.0960-7692.2001.00526.x 
[9] Sotiriadis, A., Kevvadias, A. and Papatheodorou, S. (2010) The Value of Serial Cervica Length Measurements for Prediction of Threatened Preterm Labour. European Journal of Obstetrics \& Gynecology and Reproductive Biology, 148, 17-20. https://doi.org/10.1016/j.ejogrb.2009.08.020

[10] Allaire, O. (2011) Measurement of Cervical Canal Length by Vaginal Ultrasound: Interest in the Prediction of Spontaneous Premature Delivery. Journal de Gynécologie Obstétrique et Biologie de la Reproduction, 40, 375-380.

[11] Compan, C., Rossi, A., Piquier-Perret, G., et al. (2015) Prediction of Prematurity in the Event of a Threat of Premature Delivery: Review of the Literature. Journal de Gynécologie Obstétrique et Biologie de la Reproduction, 44, 720-751.

[12] Gonzalez, N., Bige, V., Kandoussi, S., et al. (2004) Ultrasound Measurement of Cervical Length in Twin Pregnancies with Threatened Preterm Delivery: Comparison with Single Pregnancies. Gynecology Obstetrics \& Fertility, 32, 122-127.

[13] Deplagne, C., Maurice-Tison, S., Coatleven, F., et al. (2010) Sequential Use of Cervical Ultrasound Length and Detection of Fetal Fibronectin to Predict Spontaneous Preterm Birth in the Event of Threatened Premature Delivery. Journal de Gynécologie Obstétrique et Biologie de la Reproduction, 39, 575-583.

[14] Benichou, S., Maillard, F., Goffinet, F., Cabrol, D. and Schmitz, T. (2008) Comparison of Vaginal and Cervical Ultrasound in the Management of Premature Delivery Threats. The Midwife Magazine, 7, 238-242.

[15] Sotiriadis, A., Papatheodorou, S. and Makrydimas, G. (2012) Perinatal Outcome in Women Treated with Progesterone for the Prevention of Preterm Birth: A Meta-Analysis. Ultrasound in Obstetrics \& Gynecology, 40, 257-266. https://doi.org/10.1002/uog.11178

[16] Berthelot-Ricou, A., Tur, S., Guidicelli, B., et al. (2014) Prognostic Study of the Risk of Childbirth, of Patients Hospitalized for the Threat of Premature Delivery, in a Maternity Level III. Journal de Gynécologie Obstétrique et Biologie de la Reproduction, 43, 600-609.

[17] Demirci, O., Unal, A., Demirci, E., et al. (2011) Sonographic Measurement of Cervical Length and Risk of Preterm Delivery. Journal of Obstetrics and Gynaecology Research, 37, 809-814. https://doi.org/10.1111/j.1447-0756.2010.01440.x

[18] Palacio, M., Sanin-Blair, J., Sanchez, M., et al. (2007) The Use of a Variable Cut-Off Value of Cervical Length in Women Admitted for Preterm Labor before and after 32 Weeks. Ultrasound in Obstetrics \& Gynecology, 29, 421-426. https://doi.org/10.1002/uog.3950

[19] Bagga, R., Takhtani, M., Suri, V., et al. (2010) Cervical Length and Cervicovaginal HCG for Prediction of Pre-Term Birth in Women with Signs and Symptoms of Pre-Term Labour. Journal of Obstetrics and Gynaecology, 30, 451-455. https://doi.org/10.3109/01443611003802305

[20] How, H.Y., Khoury, J.C. and Sibai, B.M. (2009) Cervical Dilatation on Presentation for Preterm Labor and Subsequent Preterm Birth. American Journal of Perinatology, 26, 1-6. https://doi.org/10.1055/s-0028-1090586

[21] Bastek, J.A., Sammel, M.D., Srinivas, S.K., et al. (2012) Clinical Prediction Rules for Preterm Birth in Patients Presenting with Preterm Labor. Obstetrics \& Gynecology, 119, 1119-1128. https://doi.org/10.1097/AOG.0b013e31825503e5

[22] Schmitz, T., Kayem, G., Maillard, F., et al. (2008) Selective Use of Sonographic Cer- 
vical Length Measurement for Predicting Imminent Preterm Delivery in Women with Pre-Term Labor and Intact Membranes. Ultrasound in Obstetrics \& Gynecology, 31, 421-426. https://doi.org/10.1002/uog.5297 